\title{
Actors Determination Strategy in Registered Social Network Patents in the Framework of Rewards towards Inventors: A Case Study of LIPI Registered Patents 2016
}

\author{
Aris Yaman \\ Center for Innovation - Indonesian Institute of Sciences \\ aris.yaman@gmail.com
}

\begin{abstract}
Patent is one of the levers to improving a country's competitiveness. A reward to an inventor is one of the ways to incentivize increase in productivity and patent development in Indonesia. Social network analysis on the relationship between co-invention and registered patents can identify inventing actors who deserve the award. Joko Waluyo was determined to be the inventor who is central to the co-invention social network relationships of registered patents in LIPI. Determining the centrality of an inventor was based on the high value of betweeness and closeness to Joko Waluyo node. In addition, it was also found that a prolific inventor does not always mean that the inventor is the central actor in the social network.
\end{abstract}

Keywords: actors inventor, betweenness, closeness, co-invention, social network analysis, 


\section{INTRODUCTION}

World Economic Forum (WEF) 2016 reports that Indonesia's competitiveness has declined from 37 th position to 41 th position during 2016-2017 period. The lack of capacity of the nation to innovate is one of the factors to blame for Indonesia's low competitiveness (Figure 1) (Schwab, 2017).

In its report, The WEF notes that innovation is one of the most crucial factors in a country's competitiveness (Galvan, 2016). Acquisition of IPR and patents through $\mathrm{R} \& \mathrm{D}$ is one the solutions toward improving a country's competitiveness (Nasir, 2016).

For research and development institutions such as LIPI, it is important to increase the productivity of inventors or researchers in their institutions in producing patents. To achieve that objective, LIPI should create a policy that can encourage the interest of researchers to discover or register patents.

Furthermore, the Innovation Center is one of the units of work under LIPI, and is entrusted with duties and functions that relate to examining the possibility of intellectual property rights protection of LIPI R \& $\mathrm{D}$ works and carrying out the protection process. The policy of the Innovation Center is expected to facilitate the acquisition of patents through the "Inventor Award" program, which is a tribute to the services of LIPI researchers who produce patented research results and generate benefits to the community as well as aimed at encouraging the productivity of other researchers.

The criteria for an individual to receive the "Inventor Award" is not limited to productive in finding patents that are utilized but also must be active in encouraging other researchers to obtain their patents. To that end, it is crucially important to come up with the most appropriate method to determine the recipient of the "Inventor Award" .

One of studies in the area of scientometrics is social network analysis (SNA). Social network analysis can be used to analyze actors in a social communication network (Sulistiawati, Lubis, \& Mulyani, 2014). Social network analysis in scientometrics study generally tries to identify actors in communication network in the form of co-authorship relationship of scientific articles or citation relationship among scientific articles (Nadhiroh, Aidi, \& Sartono, 2015).

The strategy of determining actors in a social network has also been used in previous research with the objective of identifying which actors are the most instrumental in supporting the development of "startup" in Yogyakarta (by indicating frequent communications with the startup). However, the analytical approach used based on a qualitative approach (Fathin, 2016) that emphasizes an the analysis of the interaction between factors in a network. Social network analysis involves the description of the network or graph.

This network consists of nodes that represent actors in the social networks and edges that describe interactions among actors in social networks (Wasserman \& Faust, 1994; Rousseau, 2002). Social network analysis (SNA) has drawn a lot of interest, and has been widely applied in various fields of science such as anthropology, communication science, economics and accounting, geography, information and technology, management, psychology, and social linguistics. In the field of accounting information system (AIS), social network analysis is being used to predict, detect, and prevent errors or fraud in the accounting systems (Worrell, Wasko, \& Johnston, 2013). In the field of information and technology, SNA is used to identify factors responsible for security risks to computer networks (Dang-pham, Pittayachawan, \& Bruno, 2017).

As indicated earlier, actors in social network analysis are depicted by nodes. The inter-node relationship is divided into two, namely the directional relations and the non-directional relations. The directional relationships occur when the relationship runs from each actor but does not exhibit a connect back to each actor. In other words, it is a one-way relationship. The analogy that can illustrate this type of relationship is that of one way- friendship, where $\mathrm{X}$ considers $\mathrm{Y}$ as a friend, but $\mathrm{Y}$ does not necessarily consider $\mathrm{X}$ as a friend. On the contrary, nondirectional relationships are essentially 


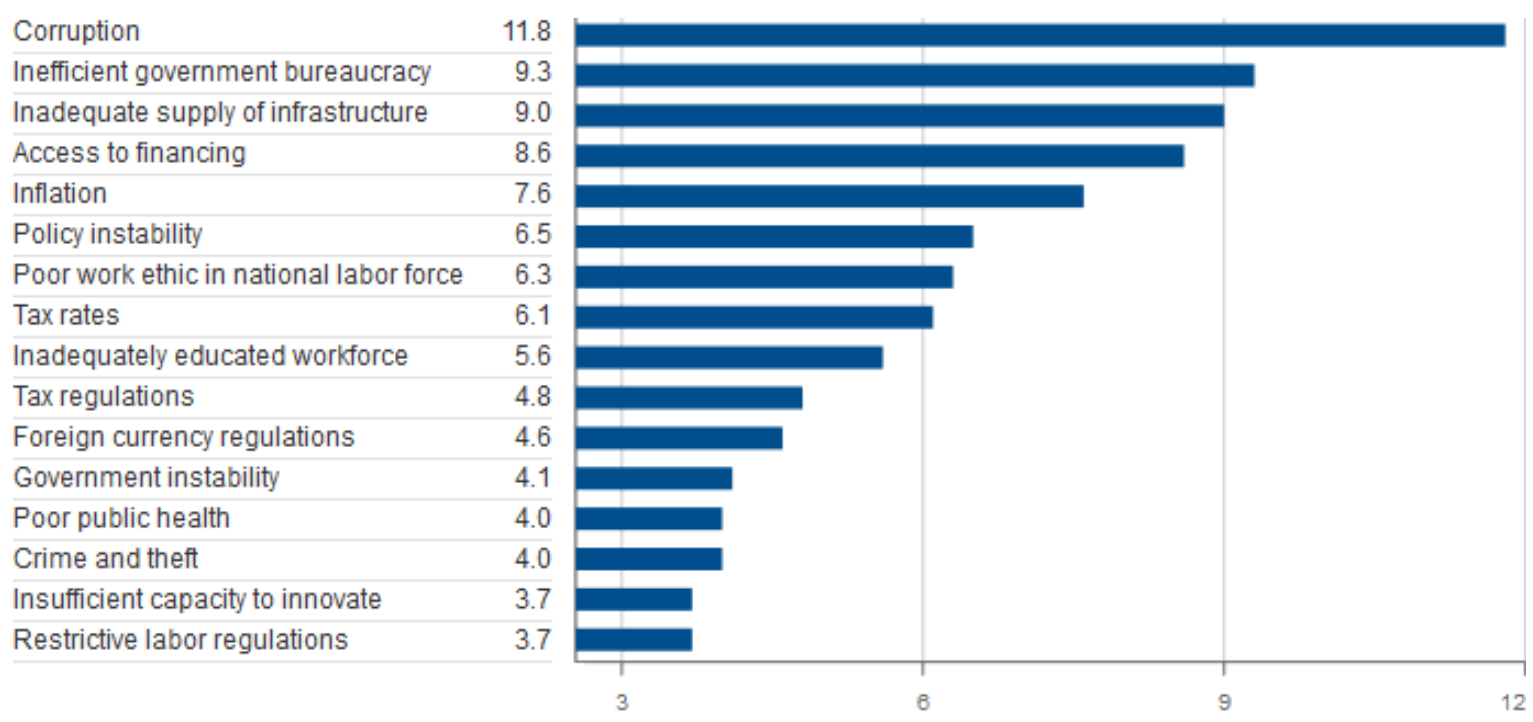

Source: Global Competitiveness Report 2016-2017

Figure 1. Factors Causing the Indonesian's Low Competitiveness

symmetrical or back and forth among principals. The analogy of the non-directional relations are relations between neighbors. When $\mathrm{X}$ is neighboring $\mathrm{Y}$, it is almost a certainty that $\mathrm{Y}$ is adjacent to $\mathrm{X}$ (Wasserman \& Faust, 1994).

Basically, determining the nature of actors (individual-level communication networks) in a social network involves three measuring instruments, interalia: the degree of centrality, the degree of betweeness, and closeness (Prell, 2012). The underlying concept of the three measuring instruments is the geodesic distance rule. The geodesic distance in the case of social networks is the shortest path between two nodes and is formulated as follows.

The value on the degree of centrality identifies the level of activity of a node in communicating with other nodes (Wasserman \& Faust, 1994). This value can be measured using mathematical equations:

Based on the formulation above, a node depicts the degree of the centrality in a so- $d(i, j)=\min \left(x_{i h}+\cdots+x_{h j}\right)$ cial The interpretation of the measure is that the higher the value the more active the node in a social network (Freeman, 1979).

In a social communication network, occasionally communication between two nodes occurs through the intermediation of

$$
c_{D}\left(n_{i}\right)=d\left(n_{i}\right)=x_{i+}=\sum_{1}^{j} x_{i j}=\sum_{1}^{j} x_{j i}
$$

other nodes. A node or actor that bridges information between two or more nodes is often considered to be an important node in the social networking structure. This is because the node that contains the bridging information characteristic has control over the information flow between two nodes or more precedent ones (Salamati \& Soheili, 2016). Carrington, Scott, \& Wasserman (2005) provides a formula for measuring the level of intermediation of a node or actor.

The formula denotes the existence of geodesic relationships between actor $\mathrm{U}$ and actor $\mathrm{V}$ through actor $\mathrm{C}$.

The degree of closeness is used to measure how close a node is in communicating with other nodes in a social network. This value is interpreted as the closer the distance of a node to other nodes the easier and faster it is to convey the information (Wasserman \& Faust, 1994). The degree of closeness is formulated as follows: 


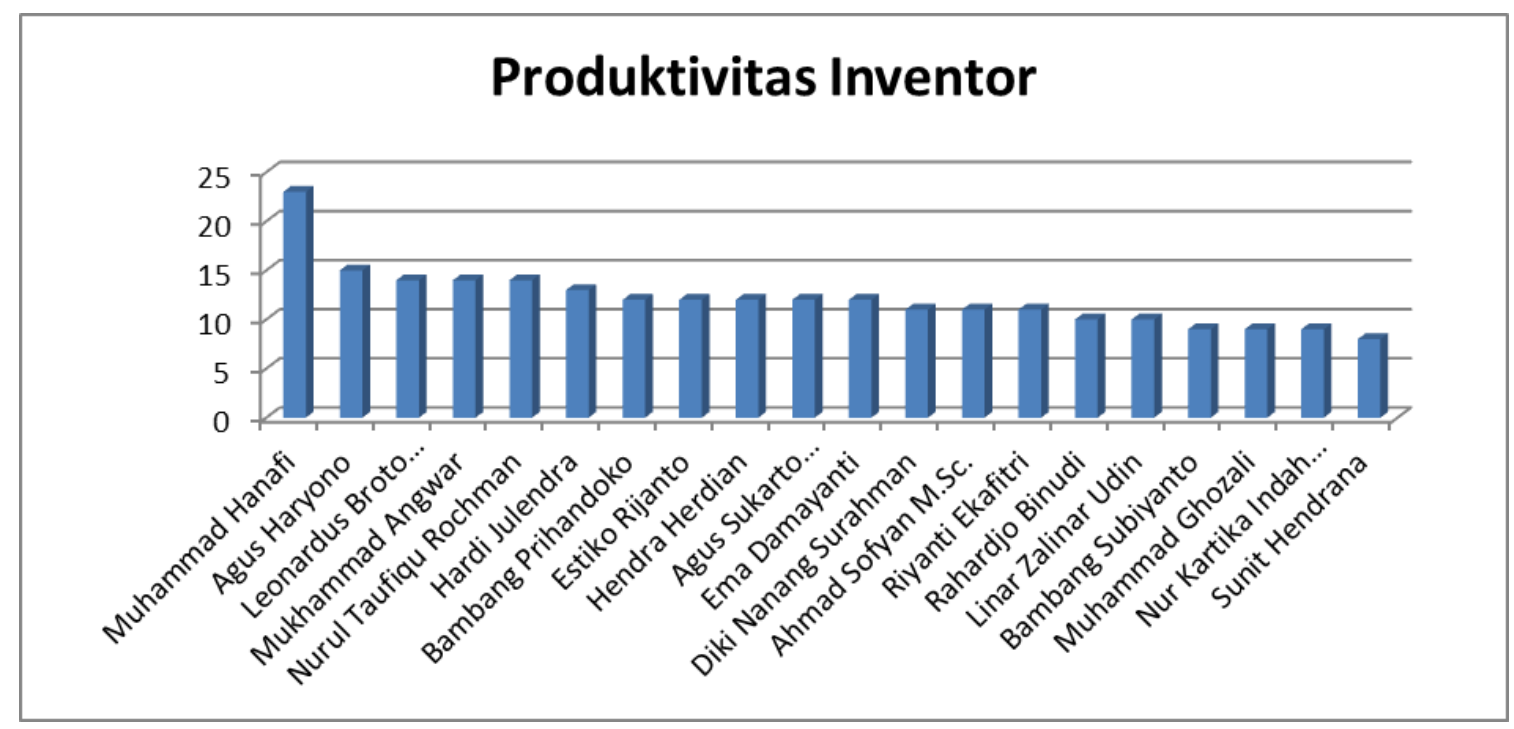

Figure 2. The Productivity of LIPI Patent Inventors

$$
\text { Tingkat kebersamaan }=\sum_{u<v} \frac{g_{u, v}(C)}{g_{u, v}}, u, v \notin C
$$

The formula explains that $g$ denotes the number of nodes in a social network, and $d\left(n_{i}, n_{j}\right)$ is the geodesic distance between $n_{i} n_{i}$ and $n_{j} n_{j}$.

Social networks analysis in the determination of the actors within the social network of patent inventors can be adapted in the determination of actors who play a significant roles in encouraging other researchers tain Closeness $=\left[\sum_{j=1}^{g} d\left(n_{i}, n_{j}\right)\right]^{-1}$ pa-

\section{RESEARCH METHODS}

The data used in this research was drawn from LIPI-registered patent data in the Directorate General of Intellectual Property Rights (HaKI). The data covers patents registered for 1991 - October 2016 period.

Social Network Analysis (SNA) was used in determining the social network of LIPI-registered patent inventors. SNA was carried out using the following stages:

1. Exploration of data to obtain a for de- scriptive view of the inventors of LIPI registered patents;

2. Identification of the co-invention relationship between the inventors by assigning a value of 1 (one) if it finds a joint patent between two inventors;

3. Preparation of the relationship matrix between any two inventors;

4. Preparation of the co-invention social network image based on the matrix;

5. Measurement of the centrality value of the inventors in the social network of the invention-inventor relationship of the registered patent LIPI (Nadhiroh et al., 2015).

\section{DISCUSSION AND RESULT}

\section{The Description of LIPI Patent Registra- tion}

In general, Table 1 depicts the level of productivity of LIPI inventors as viewed from the context of registering their patents to the HaKI

The table shows that the average productivity level of LIPI inventors is 2 patents. Meanwhile, there is a productive inventor who is associated with as many as 23 inventions. This indicates a large variation in the distribution of productivity of inven- 
Aris Yaman - Actors Determination Strategy in Registered Social Network Patents ...

Table 1. Descriptive Statistic of LIPI Inventors

\begin{tabular}{lllll}
\hline Mean & Medium & Modus & Max & Min \\
\hline 2 & 1 & 1 & 23 & 1 \\
\hline
\end{tabular}

tions in LIPI. Moreover, the table shows that most inventors only register 1 patent. Thus, based on the descriptive statistics of data on LIPI patents in Table 1 , the conclusion that can be drawn is that there are two types of researchers. One type are those who are productive researchers that register patents continuously; and those who are merely productive but cannot encourage other researchers to do what they do. In other words, the inventory cadre system does not seem work properly.

The productivity of LIPI inventors in registering their patents to the $H a K I$ is seen in Figure 2.

Figure 2 shows that based on the number of patents, the three most productive LIPI inventors in descending order are $\mathrm{Mu}$ hammad Hanafi, Agus Haryono, and Leonardus Broto. Thus, Muhammad Hanafi is the most productive inventor in LIPI with 23 registered patents.

The next section discusses the coinvention social network relationships in LIPI to analyze the inventors' "actors" in the network. The social network of the $\mathrm{co}^{-}$ invention relationships of LIPI inventors is depicted in Figure 3, Figure 4, and Figure 5. As evident in Figure 3, Figure 4, and Figure 5 , inventions occur within several social networking groups. The existence of these social networking groups attests to the existence of different characteristics in a patent, which may be attributed to the similarity of science, work units, or other features among the inventors.

Figure 3 shows the degree of centrality in the LIPI inventors' social co-invention network. With respect to the degree of centrality, Muhammad Hanafi was the highest rated inventor. This is considered reasonable because Muhammad Hanafi is the most productive inventor. The degree of centrality is linearly proportional to one's level of productivity. The more often a person invents patents along with another inventor, the more often he or she communicates with other inventors.

Meanwhile, Figure 4 shows the social network of LIPI patent inventors from the vantage point of closeness. The closeness aspect in the social network analysis of $\mathrm{co}$ invention relationships can help to identify the degree of proximity among inventors in social networks. The higher the closeness of the node, the closer the node communicates with others. In figure 4, the graph of the social network closeness of the co-invention relationship seems less clear to identify the closest closing nodes.

Table 2 explains the magnitude on the degree of centrality, closeness, and betweeness that help in determining the value of closeness of a node. Based on Table 2, Joko Waluyo is an inventor who has the largest closeness value among all inventors.

Furthermore, to identify inventors who belong to "information bridges" or flow control information in the LIPI patent invention, betweeness analysis is used. Table 2 shows that Joko Waluyo is the inventor with the largest level of information in the network. In other words, Joko Waluyo is an inventor who has the ability of enabling other inventors in his network to discover and register new patents. To that end, Joko Waluyo can be categorized as an inventor who is able to invent new inventors.

Joko Waluyo, belongs to the category of central inventors in the social network of LIPI registered patents. This is based on the judgment that Joko Waluyo is an inventor who has high closeness value to other in- 
Table 2. The Centrality Value of Social Network of the LIPI-Registered Patent CoInvention Relationship

\begin{tabular}{|c|c|c|c|c|c|c|}
\hline \multirow{3}{*}{ Inventor } & \multirow{3}{*}{ Degree } & \multicolumn{2}{|l|}{ Rank } & Rank & \multirow{3}{*}{ closeness } & \multirow{3}{*}{$\begin{array}{c}\text { Rank } \\
\text { closeness }\end{array}$} \\
\hline & & & Betweeness & & & \\
\hline & & \multicolumn{2}{|l|}{ degree } & betweenes & & \\
\hline Joko Waluyo & 16 & 6 & 67996,46 & 1 & 188.496 & 1 \\
\hline Nanik Indayaningsih & 20 & 3 & 59040,83 & 2 & 188.523 & 2 \\
\hline Suprapedi & 26 & 2 & 49991,06 & 4 & 188.580 & 3 \\
\hline Hendra Adinanta & 16 & 6 & 21890,72 & 8 & 188.613 & 4 \\
\hline Perdamean Sebayang & 11 & 12 & 3947,24 & 11 & 188.657 & 5 \\
\hline Deni Shidqi Khaerudini & 10 & 13 & 1802,99 & 13 & 188.665 & 6 \\
\hline Muljadi & 7 & 18 & 0,00 & 15 & 188.698 & 7 \\
\hline \multicolumn{7}{|l|}{ Anggito Pringgo Te- } \\
\hline tuko & 7 & 18 & 0,00 & 15 & 188.698 & 7 \\
\hline Haznan Abimanyu & 17 & 5 & 27097,55 & 5 & 188.745 & 9 \\
\hline \multicolumn{7}{|l|}{ Sabar Pangihutan Si- } \\
\hline manungkalit & 13 & 9 & 22814,13 & 7 & 188.753 & 10 \\
\hline Rahardjo Binudi & 28 & 1 & 26990,30 & 6 & 188.775 & 11 \\
\hline Hery Haerudin & 16 & 6 & 8218,17 & 10 & 188.785 & 12 \\
\hline Bambang Prihandoko & 12 & 10 & 54050,00 & 3 & 188.838 & 13 \\
\hline Muryanto & 12 & 10 & 1674,00 & 14 & 188.844 & 14 \\
\hline Edi Iswanto Wiloso & 9 & 14 & 0,00 & 15 & 188.847 & 15 \\
\hline Muchlis & 9 & 14 & 0,00 & 15 & 188.847 & 15 \\
\hline Ruslan Effendi & 9 & 14 & 0,00 & 15 & 188.847 & 15 \\
\hline Robert Ronal Widjaya & 9 & 14 & 0,00 & 15 & 188.847 & 15 \\
\hline Suryadi & 18 & 4 & 9496,74 & 9 & 188.871 & 19 \\
\hline Fredina Destyorini & 7 & 18 & 2175,78 & 12 & 188.913 & 20 \\
\hline
\end{tabular}

ventors and is also a good information regulator in the LIPI patent social network (inventors who is capable of enabling other inventors to both discover and register their patents).

In general, an inventor who is very productive in registering patents should ideally be a central actor in the registered patent social network at LIPI. However, the opposite happened with to Joko Waluyo, whose productivity was only 2 patents. (Figure 6). However, with respect to the measure of centrality of Joko Waluyo's network, he is the most renowned inventor, as stated in the previous section.

\section{CONCLUSION}

Social network analysis is effective in identifying actors in a social network of LIPI co-invention registered patent relationship. Analysis results indicate that Joko Waluyo is the central actor in the social network of the co-invention relationship of the LIPI registered patents. This due to the characteristics of Joko Waluyo as an inventor, cadre, and has a high proximity or closeness to other inventors.

Another finding is that a productive inventor in discovering and registering a patent may not necessarily be an actor in his social network, nor vice versa. In terms of patent productivity, Muhammad Hanafi is the most productive inventor but he was not the central actor in his social network.

Social networks engender the formation of social networking groups. However, to be more effective, motives of such social networking groups must be clear and 

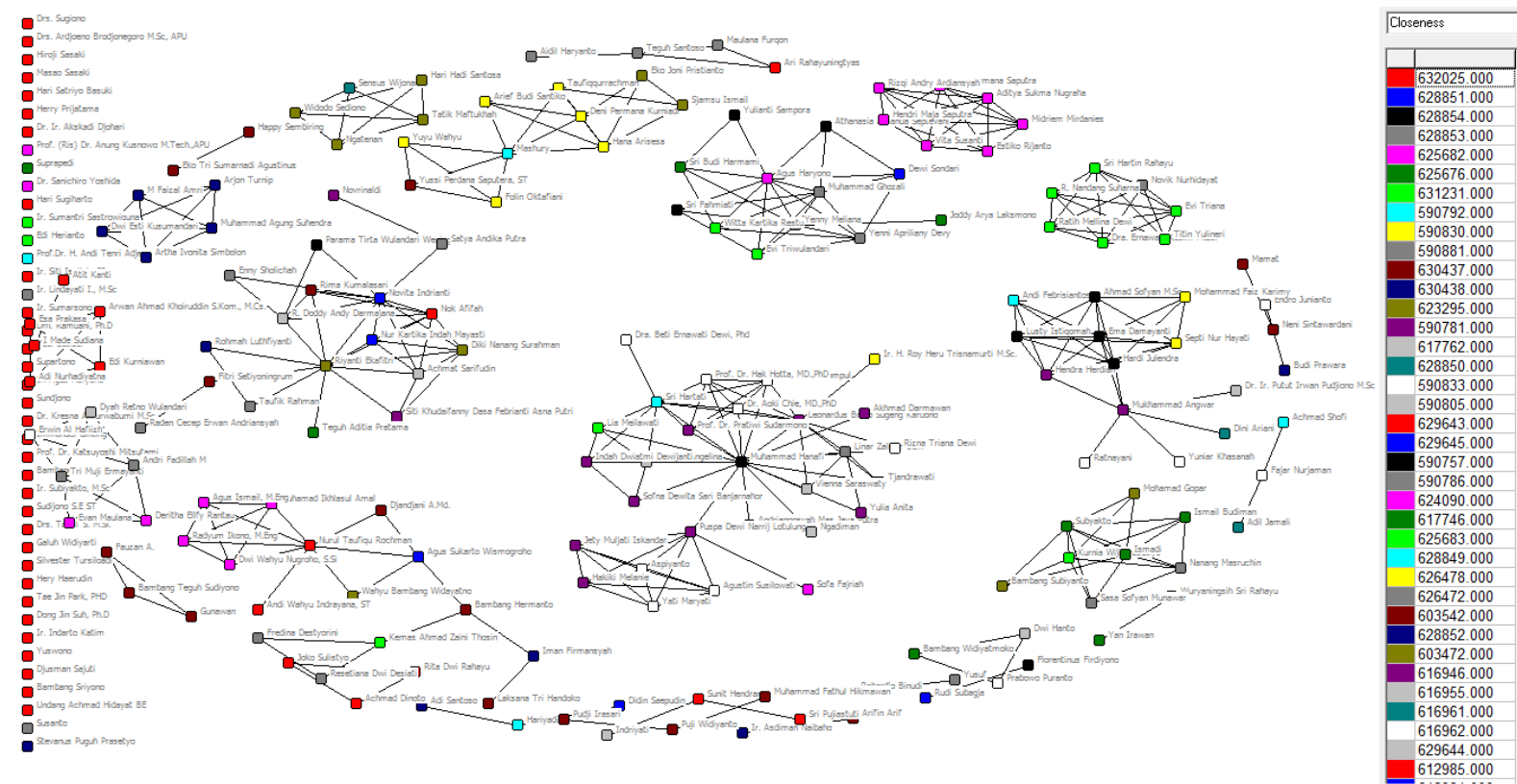

Figure 3. The Degree of Centrality of the Social Network of the LIPI-Registered Patent CoInvention Relationship

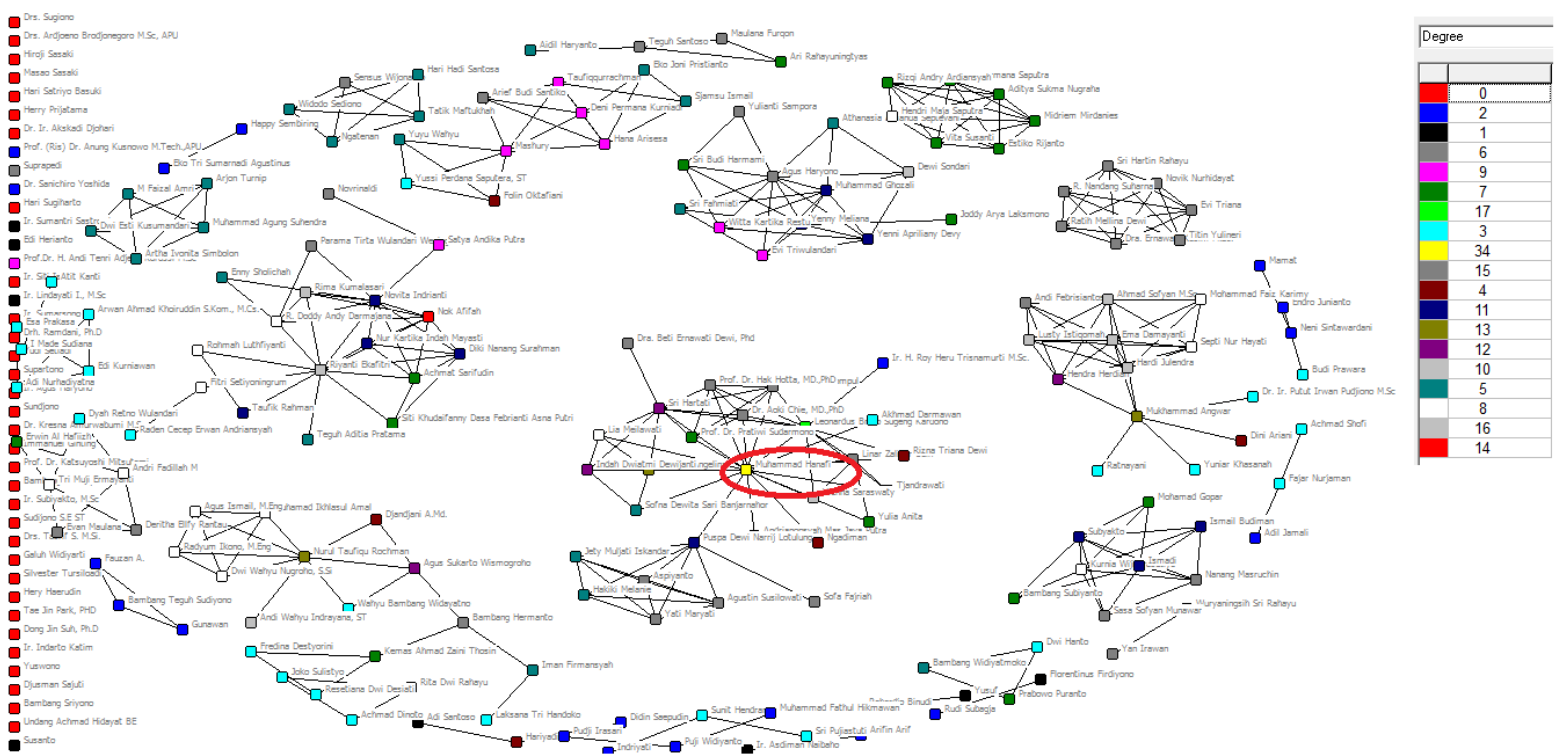

Figure 4. The Closeness of the Social Network of the LIPI-Registered Patent Co-Invention Relationship

elaborate in advance, which makes SNA of the social network easier and comprehensive. Ultimately in future, analysis of both individuals and actors on one hand, and social networking groups can be done with much ease.

\section{REFERENCES}

Carrington, P. J., Scott, J., \& Wasserman, S. 

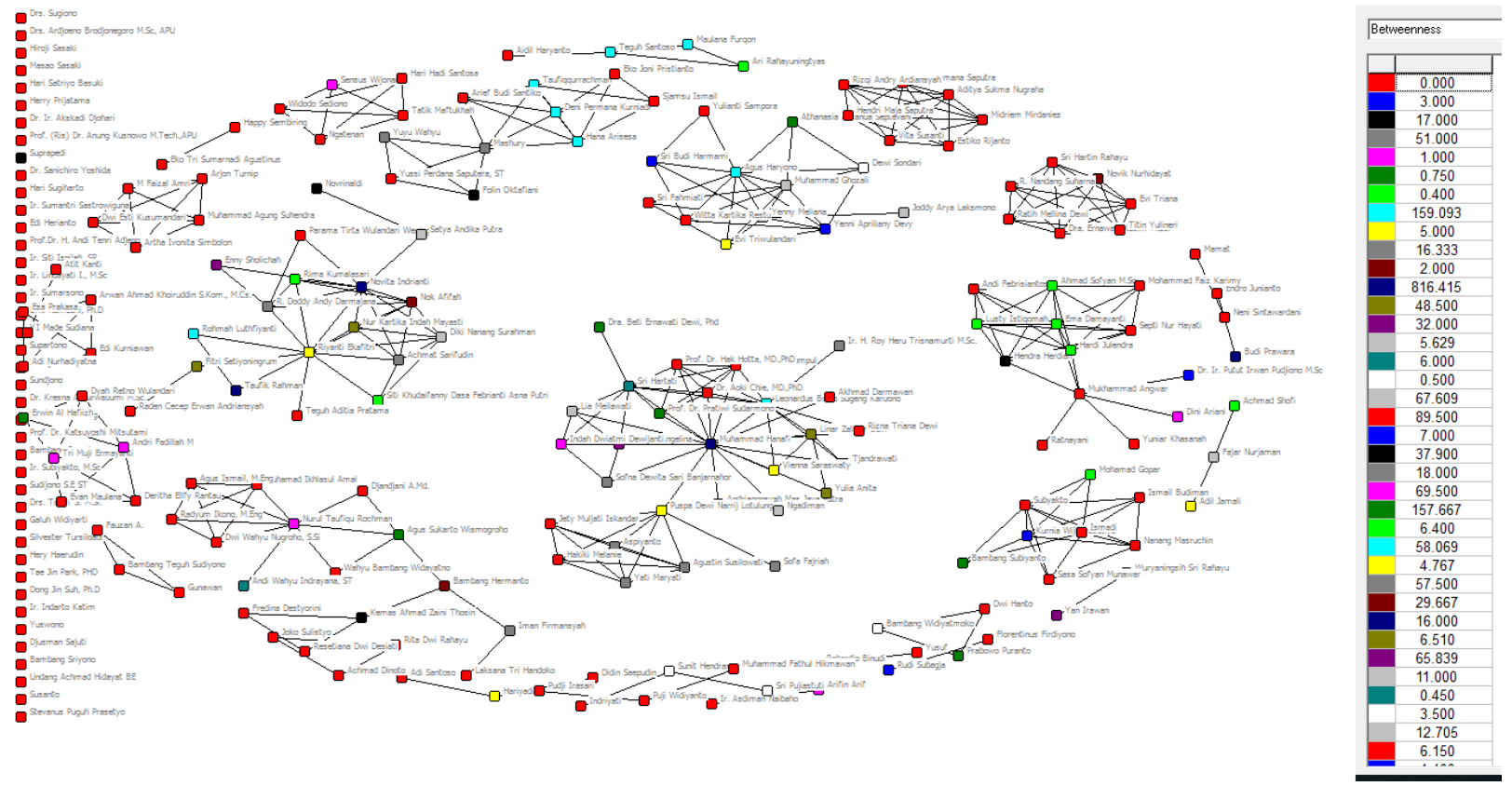

Figure 5. The Betweeness of the Social Network of the LIPI-Registered Patent Co-Invention Relationship

(2005). Models and Methods in Social Network Analysis. (P. J. Carrington, J. Scott, \& S. Wasserman, Eds.). New York: Cambridge University Press.

Dang-pham, D., Pittayachawan, S., \& Bruno, V. (2017). Why employees share information security advice? Exploring the contributing factors and structural patterns of security advice sharing in the workplace. Computers in Human Behavior, 67, 196-206. https:// doi.org/10.1016/j.chb.2016.10.025

Fathin, C. A. (2016). Analysis of Three Actors: Roles of Government, Private Sector, and University toward Startup Growth in Yogyakarta, 20(1).

Freeman, L. C. (1979). Centrality in Social Networks Conceptual Clarification, 1 (1968), 215-239.

Galvan, C. (2016). Global Competitiveness Report 2015-2016.

Nadhiroh, I. M., Aidi, M. N., \& Sartono, B. (2015). Publikasi Internasional Indonesia Bidang Kimia Scientometrics Studies : Social Network Analysis of Indonesian International Publication on
Chemistry. Warta KIML, 13, 75-90.

Nasir, M. (2016). Pendidikan Tinggin Membangun Indonesia Unggul dan Berdaya Saing.

Prell, C. (2012). Social Network Analysisn History, Theory and Methodology. Siangapore: SAGE.

Rousseau, R. (2002). Social network analysis: a powerful strategy, also for the information, 441-453. https://doi.org/ http://

dx.doi.org/10.1177/0165551502028006 01

Salamati, P., \& Soheili, F. (2016). Social network analysis of Iranian researchers in the fi eld of violence. Chinese Journal of Traumatology, 19(5), 4-10. https://doi.org/10.1016/

j.cjtee.2016.06.008

Schwab, K. (2017). The Global Competitiveness Report.

Sulistiawati, A., Lubis, D. P., \& Mulyani, S. (2014). Analisis Jaringan Sosial Dalam Gabungan, 2(2), 76-82.

Wasserman, S., \& Faust, K. (1994). Social Network Analysis : Methods and Analy- 
Aris Yaman - Actors Determination Strategy in Registered Social Network Patents ...

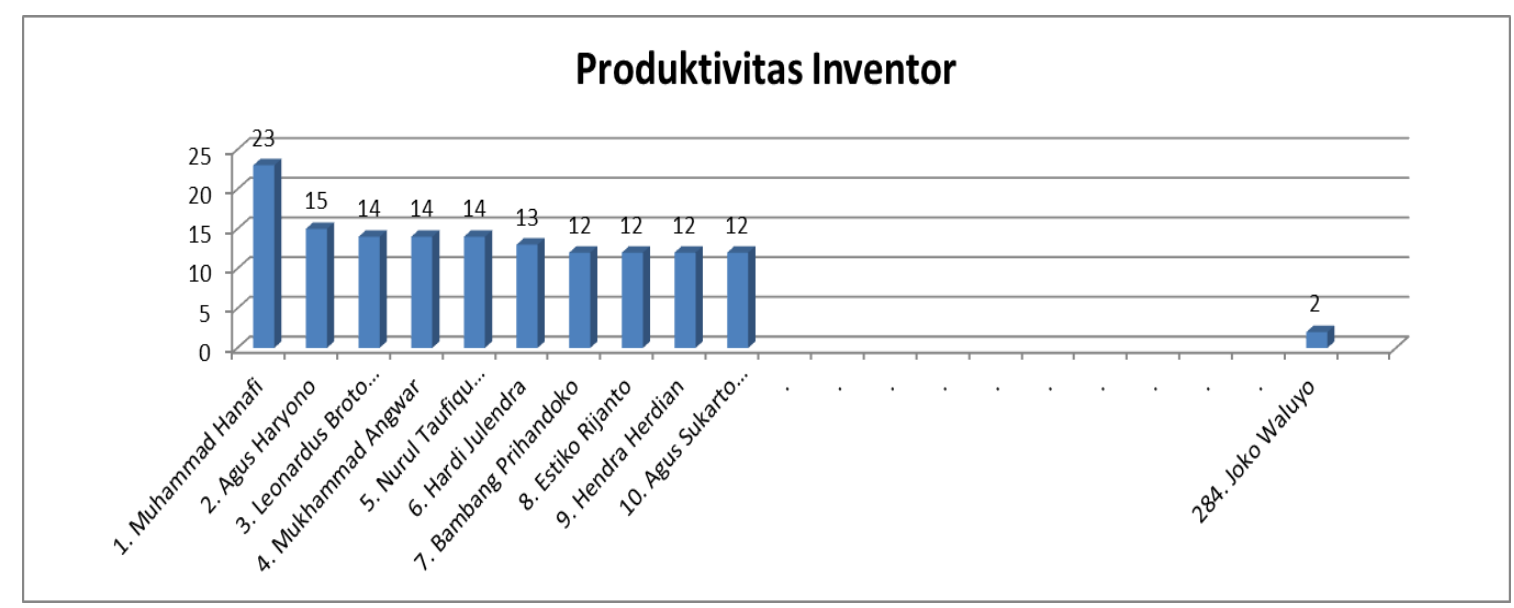

Figure 6. The Comparison of Productive Inventors to the Social Network Inventing

\section{Actors}

sis (Vol. I). New York: Press Syndicate of the University of Cambridge.

Worrell, J., Wasko, M., \& Johnston, A. (2013). International Journal of Accounting Information Systems Social network analysis in accounting information systems research. International Journal of Accounting Information Systems, 14(2), 127-137. https:// doi.org/10.1016/j.accinf.2011.06.002 